\title{
Folk Songs and Material Culture in Medieval Central Europe: Old Stones and New Music. By Nancy van Deusen.
}

Turnhout: Brepols, 2019. 279 pp.

\section{Antonio Chemotti}

Institute of Art of the Polish Academy of Sciences, Department of Musicology, Długa 26/28, 00-238 Warszawa, Poland; antoniochemotti@hotmail.it

Nancy van Deusen's Folk Songs and Material Culture in Medieval Central Europe: Old Stones and New Music is the sixth volume in the series Studies in the History of Daily Life (800-1600), published by Brepols. When the editors of the present journal proposed that I write a review of this monograph, I gladly accepted: I am a musicologist specialising in late-medieval and early modern Europe, and I have a particular interest in the music performed in the rural areas of fifteenth-and sixteenth-century Central Europe. Thus, I was eager to read the book, as its title seemed to promise a discussion of a fascinating yet slippery topic: in historical musicology that deals with medieval and early modern Europe, the very term 'folk song' has largely fallen out of fashion and numerous scholars doubt that we have access to the 'folk music' of those epochs at all. I soon realised, however, that both the title and the book's inclusion in the abovementioned series are rather misleading: van Deusen's monograph is not devoted to songs in medieval Central Europe, and nor does it discuss the daily life of medieval Central Europeans. Rather, her study is an attempt to deconstruct, primarily, twentieth-century research on folk songs in Hungary by recovering conceptual tools developed by medieval thinkers and highlighting, moreover, the traits common to folk song research and the study of medieval chant. By dealing 'with the present through the attainments of the past' ( $\mathrm{p}$. xi), the book commendably pleads for 'breaking down boundaries between historical studies and ethnomusicology' and argues for a 'comparative methodology that transcends the arbitrary borders of time and space' (pp. xii-xiii). The 'old stones' of the title refer to the 'building material' appropriated from the past-the latter treated as a quarry-recombined to create something new. In van Deusen's argumentation, this architectural metaphor resonates with the medieval conception of substance as a 'silva' (literally, a 'forest full of trees'); a repository of pre-existing substance to be used (see the useful glossary on pp. 243-248). Van Deusen applies this main concept-creation 
through the combination of pre-existing chunks of substance-to a wide range of topics: for instance, Herder's working procedure (p. 29), the psalm Beatus vir (p. 112), the constructive process of chants and folk songs (pp. 118-119), the activity of individual singer-composers who collect folk melodies (p. 198), and so on. Mixing up such diverse sources and tracing connections is probably what van Deusen regards as a way to avoid the abovementioned borders of time and space. On p. 53, for instance, she exposes the structural correspondences-'the bringing together of "chunks" - between a paragraph from a discourse by Kodály (delivered in 1963), folk music, and medieval and Byzantine composition of the ninth-tenth century. The approach is courageous, yet it appears utterly arbitrary to a reader like myself, trained in historical musicology.

This is not to say that there are no important points raised in this book; quite the contrary. In Chapter 3 (pp. 37-56), for instance, Van Deusen discusses the limits of many concepts currently used for analysing and categorising both medieval and folk music. She argues that common dichotomies found in scientific literature (such as rural/urban, folk/cultivated, natural/artificial) 'often in real life, with examination, and in comparison with the realities of life, break down' and that they are 'constructs perceived as useful in analysis, reiterated in the telling, repeated perhaps through decades of scholarly literature' but that 'may reflect neither the circumstances described nor the perceptions, actually, of those who have described them' (p. 38). In Chapter 4 (pp. 57-81), instead, she recovers a medieval conceptualisation of sound as material by discussing the medieval reception of Plato's Timaeus, focussing in particular on Chalcidius' rendition of the Greek 'hyle' as 'silva'; a concept that plays a central role in van Deusen's argumentation that goes beyond the realm of medieval studies, as mentioned above. The very idea of using the medieval equipment of concepts to provide methodological input to twenty-first-century research is an inspiring form of anachronism that should not be dismissed too easily. All in all, however, I found it extremely difficult to follow the reasoning behind Folk Songs and Material Culture in Medieval Central Europe: to re-use van Deusen's metaphor, the book appears to me to be composed of chunks, yet one put together with no compelling logic.

Furthermore, van Deusen often refers to her own experiences as a foreigner in Budapest, using them not only to lighten the scientific prose (successfully), but also to illustrate some fundamental points of her argumentation (in my opinion, less successfully). In Chapter 8 (pp. 147-157), for instance, she tackles the 'passion for collection' that characterised both historical musicology and folk music research, tracing in particular methodological similarities between the study of medieval sequences and twentieth-century folk songs. She seems to think that a collecting attitude was (or is) particularly strong in Hungary, and she introduces 
the chapter by sketching Hungarian research culture as a culture 'of gathering, of community, of the never-ceasing web of human contact, of constant exchange and conversation' (p. 147). She does so by recounting a day spent in the library of the Musicology Institute of the Hungarian Academy of Sciences: 'the "librarian" (or caretaker of the reading room) is speaking loudly on the telephone, after it has also insistently rung many times, workmen are working outside of the windows, an assistant is typing cards on a manual typewriter, and the research colleague is, as he has told me, under desperate pressure to finish a paper he is going to give soon and is flapping through the large-format pages of the collected edition of the composer's works with which he has to do. Colleagues come in and out, greeting and chatting with one another, as has been the case in the same way for decades' (p. 147). She concludes the anecdote noting that, 'for a "Westerner", it is an impossible situation, and in this context, it is of interest that, by contrast, the New York-based, North-American-influenced Central European University Library across the Danube informs those entering the reading room that "Silence must be maintained at all times"' (pp. 147-148). Van Deusen sees in this contrast not only a difference between the library cultures of North America and Hungary, but also a manifestation of a precise methodological tradition: 'What kinds of mental work can be accomplished under these circumstances? For what is this environment conducive? The answer is: collecting' (p. 148). Besides the fact that I cannot see the relation between collecting melodies-a work that, in my experience, requires a high level of concentration - and a loud working space, I wonder about the relevance and the scientific value of such anecdotes, which appear over and over in the course of the book (see, for instance, pp. 7-8, 37-38, 83, 99-101, 124, and 193). Furthermore, all too often I find van Deusen to be too quick to identify relations between intellectual traditions and socio-political features: in Chapter 10, devoted to nationalism and folk music, she seems to suggest that the passion for collection she finds in Hungarian musicology is a reaction to a 'tendency to fragmentation in this part of the world', exemplified, for instance, 'by the fact that my colleagues at universities in Budapest needed several different jobs to make a modest living' (p. 179). An interesting hypothesis that would call for solid evidence, especially in a scientific publication.

To conclude, van Deusen's Folk Songs and Material Culture in Medieval Central Europe is a most curious book. The irritation I experienced while reading it was certainly also due to its experimental character: given the publisher and the series in which the book appeared, I expected a 'traditional' study of historical musicology, and my expectations were frustrated. This said, I see nonetheless a short circuit between this publication and its intended readership: van Deusen states in the preface that 'it is hoped that its reading audience will include not only historical 
musicologists and medievalists, but also a much wider audience of ethnomusicologists and those interested in cultural studies' (p. xi). Given this objective, a clearer structure and more convincing argumentation-convincing by the methodological standards of the disciplines van Deusen wants to connect-would have been advisable.

() 2021 The Author(s).

(c) (i) This is an open-access article distributed under the terms of the Creative Commons Attribution-Non Commercial 4.0 International Licence (CC BY-NC 4.0). 